\title{
Epidemiologia e saúde bucal coletiva: um caminhar compartilhado
}

\author{
Epidemiology and public health dentistry: \\ a shared walkway
}

Angelo Giuseppe Roncalli 1

\footnotetext{
1 Universidade Federa do Rio Grande do Norte. Av. Senador Salgado Filho 1787, Lagoa Nova, 59056-000, Natal RN. roncalli@ufrnet.br
}

Abstract The public health dentistry is a way to bring oral health to Brazilian National Health System (SUS) and vice-versa. Thus, the epidemiology, in this context, it is one of the most important allies. In this article we intend to discuss the "shared walkway" between epidemiology and public health dentistry, through two views: first, we analyzed the efforts to establish methodological models for oral health sectional studies and the possibilities to construct a national data base. Second, we discussed how this knowledge has been transformed in a qualified scientific production presented in meetings and papers, which reflects, at the same time, about the contribution of this process in the consolidation of public health dentistry field. We concluded that this "shared walkway" was (and still is), influenced by political aspects, which, in different moments, leads to an improvement of public health dentistry. The oral health epidemiology has been established as a knowledge area, with regard to the scientific production in Brazil. At the same time, provide a tool that contributes to make oral health care models more appropriate to National Health System principles and, in other hand, make better the discussions about the social determinants of oral diseases.

Key words Epidemiology, Public health, Oral health
Resumo A saúde bucal coletiva, na medida em que surge como um modo de trazer a saúde bucal para o SUS (e vice-versa), tem, na epidemiologia, um de seus mais contundentes aliados. Este artigo discute o modo como se deu esse caminhar, trilhado compartilhadamente, entre a saúde bucal coletiva e a epidemiologia. Analisa, inicialmente, os esforços na tentativa de estabelecer modelos metodológicos para pesquisas transversais, bem como a possibilidade da construção de uma base de dados nacional. Num segundo momento, discutese como esse conjunto de conhecimentos tem se corporificado em uma produção científica qualificada e compartilhada com seus pares, refletindo sobre o modo como este processo vem contribuindo para a consolidação do campo da saúde bucal coletiva. Percebe-se que este caminhar compartilhado esteve e está condicionado pela conjuntura politica que, em momentos distintos, proporcionou o crescimento da saúde bucal coletiva. A epidemiologia em saúde bucal, ao mesmo tempo em que se consolida como área de conhecimento no plano da produção científica no Brasil, articulase com este movimento, proporcionando, de um lado, uma ferramenta que aproxima os modelos assistenciais em saúde bucal do ideário do SUS; e, de outro, aprofunda as discussões a respeito dos determinantes biopsicossociais das doenças bucais.

Palavras-chave Epidemiologia, Saúde coletiva, Saúde bucal 


\section{Notas introdutórias e algumas questões conceituais}

Uma definição muito comum e bastante difundida da epidemiologia foi proposta por Last ${ }^{1}$, conceituando este campo do conhecimento como o estudo da distribuição e dos determinantes de estados ou eventos relacionados à saúde em populações específicas, e a aplicação desses estudos no controle dos problemas de saúde.

É oportuno lembrar, entretanto, o destaque de Scliar2, que acrescenta o próprio sentido de existir da epidemiologia quando elabora seu conceito: [epidemiologia] é o estudo dos fatores que condicionam o surgimento e a distribuição de fenômenos ligados à saúde e à doença, bem como o uso deste estudo para melhorar as condições de saúde da população (grifo nosso).

No campo da saúde coletiva, portanto, são inúmeras as aplicações do conhecimento epidemiológico, particularmente as que estão articuladas ao planejamento e à avaliação dos serviços de saúde. No caso brasileiro, o uso da epidemiologia nos serviços de saúde é previsto em lei, tendo, portanto, suporte no campo jurídico-legal. A Lei 8080 de 1990, em seu capítulo II, artigo 7, diz que, no desenvolvimento de ações e serviços de saúde, deve haver "a utilização da epidemiologia para o estabelecimento de prioridades, a alocação de recursos e a orientação programática" (Goldbaum³).

Um outro aspecto fundamental é que o diagnóstico de saúde, proporcionado pela epidemiologia, está inserido dentro das estratégias globais de planejamento e avaliação nos serviços de saúde. Em outras palavras, isso quer dizer que não devem ser momentos estanques ou anteriores às ações de saúde, mas o chamado "enfoque epidemiológico" dos serviços deve ser uma prática transversal e cotidiana. Para Teixeira ${ }^{4}$, mesmo quando se considera a evolução das estratégias de planejamento na América Latina, desde o método Cendes-Opas, a epidemiologia surgia, tradicionalmente, como uma disciplina instrumental e subsidiária, responsável apenas pelo diagnóstico de saúde. A partir da compreensão da necessidade de uma visão estratégica de planejamento, a epidemiologia passa a ser encarada como uma perspectiva de trabalho, numa abordagem mais ampla. No caso brasileiro, os modelos assistenciais estabelecidos a partir do Sistema Único de Saúde (SUS) têm colocado a epidemiologia como eixo estruturante para suas estratégias de gestão.
$\mathrm{Na}$ área de saúde bucal, o surgimento de um modelo de saúde universal e eqüitativo, pressuposto de uma política de Estado de forte base social, como foi o SUS proposto na Constituição de 1988, trouxe um significativo desafio aos tradicionais modelos de oferta de serviços odontológicos, baseados nos sistemas escolares e de livre demanda nos serviços de saúde (Narvai5, Zanetti et al.6). A utilização da epidemiologia, base para a elaboração de modelos mais eficientes, eficazes, efetivos e eqüitativos, era, além de rara, feita de modo essencialmente instrumental, em modelos de caráter excludente e focalizador.

A chamada "saúde bucal coletiva" surge, pois, no bojo desse desafio e dessas inquietações. A aparente contradição do termo - tendo em conta que o "bucal" é, em certa medida, uma particularização do corpo e o "coletivo" é uma negação desta particularização, com conseqüente ampliação para o nível da sociedade não desqualifica sua força ideológica ou mesmo operacional. Ao mesmo tempo em que alarga seu próprio microcosmo, saindo de uma abordagem eminentemente "odontológica" para algo mais amplo como a "saúde bucal", a "saúde bucal coletiva" expressa o esforço desse processo de ruptura sair do plano do indivíduo e alcançar o plano da coletividade. Desse modo, supera o desgaste dos termos "odontologia" e "social" (ou mesmo sanitária, comunitária, etc.), como bem aponta Narvai5. Este "conceito em permanente construção" (Botazzo 7 ) é, ao mesmo tempo, um modo de identificar essa "tribo" de indivíduos que militam nos mais distintos espaços, em particular naquilo que convencionamos chamar de "academia" (universidades, centros de pesquisa) e nos serviços de saúde.

Assim, a saúde bucal coletiva tem sido forjada dentro dos movimentos sociais, em particular o movimento pela Reforma Sanitária Brasileira, e no interior da academia, a partir de movimentos contra-hegemônicos, que transformaram a tradicional "odontologia social e preventiva" em propostas mais articuladas com a saúde coletiva.

$\mathrm{Na}$ medida em que a saúde bucal coletiva surge como um modo (ideológico, operativo, contra-hegemônico) de trazer a saúde bucal para o SUS (e vice-versa), de romper com modelos excludentes e de avançar em um novo modo de fazer saúde bucal, a epidemiologia se insere como um de seus mais contundentes aliados.

Este artigo pretende, portanto, discutir o modo como se deu esse caminhar, trilhado, 
compartilhadamente, entre a saúde bucal coletiva e a epidemiologia (em saúde bucal). Tal discussão se desenvolverá em dois eixos. No primeiro deles, abordaremos o modo como tem se dado a apropriação do conhecimento epidemiológico pela saúde bucal coletiva em sua vertente assistencial, ou seja, de que maneira a construção de modelos de atenção em saúde bucal de "base epidemiológica" tem dado conta de superar os desafios da implementação do SUS ao longo da década de 1990. Nesta perspectiva, consideraremos um dos aspectos dessa temática: os esforços em nível federal na tentativa de estabelecer modelos metodológicos para pesquisas transversais, bem como na possibilidade da construção de uma base de dados nacional. Num segundo eixo, abordaremos como esse conjunto de conhecimentos, apropriado pela academia e pelos serviços, tem se corporificado em uma produção científica qualificada e compartilhada com seus pares. Em outras palavras, discutir o amadurecimento da epidemiologia (em saúde bucal), expresso na sua crescente participação em conclaves da área, e o modo como este processo vem contribuindo para a consolidação do próprio campo da saúde bucal coletiva.

\section{A epidemiologia e a saúde bucal no SUS: o desafio da construção de modelos de base epidemiológica}

As experiências do uso da epidemiologia nos serviços de saúde bucal no Brasil são, de fato, muito tímidas. Considerando as duas principais alternativas de produção de dados epidemiológicos, seja a partir de dados secundários produzidos pelos serviços de saúde, seja pela geração de dados primários oriundos de pesquisas epidemiológicas transversais (os conhecidos levantamentos epidemiológicos de saúde bucal), os modelos assistenciais em saúde bucal pouco têm se apropriado deste arsenal. Em termos de produção de uma base de dados nacional, o Brasil se insere muito tardiamente neste processo, levando-se em conta que boa parte dos países desenvolvidos apresenta séries históricas desde as primeiras décadas do século 20, ao passo que o Brasil realizou seu primeiro grande levantamento somente na metade da década de 1980 (Brasil8).

Obviamente, colocar na pauta a discussão a respeito do uso da epidemiologia pelos serviços de saúde bucal exigiria a inclusão de outros pontos importantes, como a sua incorporação pelos modelos assistenciais, as principais características de sua prática, sua articulação com estratégias de vigilância e com outros mecanismos de produção e disseminação de dados e informações, entre outros. Entretanto, neste artigo iremos nos deter num desses aspectos: a produção de dados epidemiológicos em âmbito nacional.

\section{A construção de diagnósticos coletivos: experiências nacionais de levantamentos epidemiológicos}

Podemos considerar que as principais experiências de produção de dados em nível nacional se resumem aos três levantamentos epidemiológicos em saúde bucal levados a cabo em 1986, 1996 e 2003. Tais experiências representam o esforço do setor saúde bucal em nível federal de, por um lado, produzir dados que componham uma série histórica consistente que possa contribuir como subsídio para a elaboração e a avaliação de políticas públicas; e, por outro lado, propor modelos metodológicos razoavelmente padronizados para o Brasil. Cada uma dessas três experiências expressa, de modo muito claro, tanto o acúmulo técnicometodológico vivido pela saúde bucal coletiva e pela epidemiologia, quanto o desenvolvimento político do setor saúde bucal enquanto espaço de intervenção na política em nível nacional, nos três momentos distintos.

A primeira grande experiência foi conduzida em 1986 pela então recém-criada Divisão Nacional de Saúde Bucal (DNSB), tendo seu relatório sido publicado somente em 1988 (Brasil8). Na verdade, segundo Zanetti9, a DNSB foi criada em 1987 com o levantamento já iniciado através de sua estrutura equivalente no Ministério da Saúde, o GT-Odonto. Ainda segundo esse autor, esse levantamento fazia parte de uma proposta de atuação geral da DNSB, que incluía três grandes vertentes: os serviços de epidemiologia, os de programação e normas técnicas e os de recursos operacionais.

Segundo o relatório do levantamento, três argumentos principais levaram à realização da pesquisa: em primeiro lugar, o reconhecimento de que somente com dados fidedignos tornar-seia possível o desenvolvimento de ações preventivas, educativas e curativas com a necessária amplitude no país; segundo, a evidência de que a 
demanda por serviços odontológicos é limitada; [...] e, finalmente, em terceiro lugar, a possibilidade cada vez mais próxima e concreta de implementação de um programa nacional de saúde pública em odontologia, para o qual esses subsídios são essenciais (Brasil8). Em suma, de uma maneira ou de outra, falava-se, de modo concreto - provavelmente pela primeira vez em caráter nacional -, no estabelecimento de um modelo de atenção à saúde bucal de base epidemiológica.

É importante destacar, nesse contexto, a conjuntura histórico-política pela qual passava o País na ocasião. O Brasil começava a sair de um período de ditadura militar imposto desde 1964. Havia apenas dois anos contava com um presidente civil eleito por voto indireto (em 1984). No campo da saúde, a histórica 8 a Conferência Nacional de Saúde, em 1986, consolidava a opção institucional do movimento da reforma sanitária, demarcando seu campo de atuação e apontando para os significativos avanços conquistados dois anos depois, na Constituição de 1988.

Do ponto de vista técnico, a pesquisa de 1986 foi resultado de um acúmulo que levou à incorporação, por um lado, das técnicas de pesquisa com escolares, para as crianças de 6 a 12 anos; e, de outro, da modelagem amostral na pesquisa em domicílios, para os grupos etários de adolescentes, adultos e idosos (Roncalli10).

Apesar de todo esse esforço, considerando que o levantamento trouxe informações muito ricas e que são utilizadas até hoje em análises do perfil epidemiológico brasileiro, essa primeira experiência em nível federal não se estabeleceu enquanto rotina e nem enquanto componente de uma estratégia mais global de uso da epidemiologia nos serviços. Não contribuiu, tampouco, para a composição de uma base de dados pública que apontasse para a estruturação de uma estratégia de vigilância em saúde bucal. A política de saúde bucal ao qual o levantamento esteve vinculado, o Programa de Prevenção da Cárie Dentária (Precad), resumiu-se a um tímido estímulo à fluoretação das águas e à implementação de um programa de aplicação tópica de flúor gel em escolares, o qual se mostrou de baixa cobertura e efetividade. De outro lado, a divulgação dos dados se restringiu ao relatório do levantamento, o banco de dados só se tornou público mais de dez anos depois e, até o presente momento, os dados não estão disponíveis no Sistema Datasus.
A conjuntura política que se seguiu explica, em parte, essa ausência de continuidade. A partir de 1989 , com a subida ao poder do primeiro presidente eleito pelo voto direto, ao mesmo tempo em que se inicia uma nova fase na democracia brasileira, evidencia-se a entrada do Brasil no conjunto de nações que optaram pela vertente econômica neoliberal, traço marcante das políticas econômicas da América Latina ao longo do fim dos anos 80 e de toda a década de 1990. São anos difíceis para o processo de implantação do Sistema Único de Saúde (SUS), previsto na Constituição de 1988 e ancorado em pressupostos de uma política de saúde de caráter universal (Noronha \& Soares ${ }^{11}$ ).

No nível federal, a saúde bucal ficou esvaziada por longo período, pelo menos durante a era Collor. Retomada de modo mais efetivo somente no governo FHC, já não mais como Divisão, mas como Coordenação e depois como Área Técnica de Saúde Bucal, uma das primeiras iniciativas da nova gestão foi realizar um novo levantamento epidemiológico, em 1996 (Souza12, Roncalli10). A experiência acumulada com a pesquisa de dez anos antes foi aproveitada apenas parcialmente, o que reforça a tese anterior de uma total ausência de continuidade nas práticas epidemiológicas em termos de política nacional. Pode-se considerar que houve um retrocesso em relação a 1986, uma experiência que poderia ter sido aperfeiçoada, uma vez que o levantamento se restringiu a escolares de 6 a 12 anos, avaliando somente cárie dentária. O plano amostral, uma adaptação linear e acrítica da metodologia proposta pela OMS em 1987, era extremamente deficiente, com definição inadequada do tamanho e com processos de composição da amostra a partir de critérios não-probabilísticos (Pinto13, Roncalli10).

Assim, de uma maneira geral, a experiência de 1996 é a nítida expressão do amadorismo com o qual foi conduzido o processo, bem como da força política e da inserção institucional do setor saúde bucal, ambas nitidamente frágeis durante boa parte da década de 1990. À semelhança do levantamento anterior, não houve capilarização da experiência em outros pontos do País, não se estabeleceu uma linha metodológica e o processo de publicização dos resultados foi extremamente disperso. O relatório final não chegou a ser publicado, apesar de os dados estarem disponíveis para tabulação na plataforma Tabnet do Datasus.

No início de 1999, começa a ser gestado, no âmbito do Ministério da Saúde, o projeto do 
que viria a ser a terceira experiência de levantamentos epidemiológicos em saúde bucal, o Projeto SB2000 - Condições de Saúde Bucal da População Brasileira, posteriormente denominado SBBrasil 2003. O Projeto SB2000 surge como uma proposta ambiciosa de recuperar boa parte das deficiências de estudos anteriores, no sentido de compor um diagnóstico consistente no início da nova década, século e milênio (Roncalli et al.14).

Do ponto de vista metodológico, esse projeto avança ao propor um estudo que abrange um número considerável de municípios (250 ao todo, 50 em cada região), superando a restrição dos estudos realizados somente em capitais, além de incluir a região rural. Pela primeira vez são incluídos, em um estudo nacional, municípios de pequeno porte. Outras inovações incluem a avaliação de praticamente todos os agravos mais importantes na área de saúde bucal (cárie dentária, doença periodontal, edentulismo, oclusopatias e fluorose) e uma composição de grupos etários que engloba todo o ciclo da vida. Além disso, foi incluída uma avaliação qualitativa, composta de três dimensões: condição socioeconômica, acesso a serviços de saúde e autopercepção de saúde bucal (Roncalli et al.14).

Pode-se dizer que o SBBrasil, a despeito de suas reconhecidas limitações, configura-se como um marco na epidemiologia em saúde bucal no Brasil, por várias razões. Em primeiro lugar, conseguiu se estabelecer um diagnóstico aprofundado da situação de saúde bucal no Brasil, evidenciando pontos nunca antes analisados, estando entre os mais relevantes as desigualdades regionais e o perfil de doenças as quais ainda não conhecíamos sua expressão em termos regionais e nacionais, como as oclusopatias e a fluorose dentária.

Em segundo lugar, sua base metodológica permite comparabilidade internacional, além de, no plano interno, estabelecer uma base que torna possível sua replicação nos mais diferentes níveis, desde uma pequena localidade até grandes metrópoles. Diversos municípios, e mesmo estados, já desenvolveram estudos com a metodologia proposta.

Um terceiro e importante aspecto foi o fato de que, na medida em que o processo de construção e execução do projeto foi compartilhado com diversas instituições (secretarias estaduais e municipais, entidades e universidades), se desenvolveram, embora de modo distinto nos vários estados e municípios, dois fenôme- nos importantes. Um deles foi a criação (ou aprimoramento) de uma "expertise" epidemiológica nos serviços que, em função das características técnicas e políticas das secretarias de saúde, se institucionalizou com diferentes magnitudes (ou mesmo não se institucionalizou). Em outra ponta, toda a metodologia utilizada - desde o delineamento amostral até as técnicas de treinamento e calibração e os instrumentos de coleta - foi publicizada e divulgada, de tal modo que acabou sendo absorvida por grande parte da academia e dos serviços. Pelo menos três publicações recentes, uma já disponível (Pereira15) e duas no prelo, incluem capítulos com a descrição da metodologia utilizada na pesquisa. Diversas escolas de odontologia passaram a incluir, em seus programas relativos à epidemiologia, a base metodológica do Projeto SBBrasil.

Finalmente, a arquitetura da pesquisa foi pensada no sentido de criar uma matriz para a construção de um modelo de vigilância em saúde bucal a partir da geração de dados primários. Tal processo tem tido um caminhar mais lento, muito em função das características históricas da construção dos modelos assistenciais em saúde bucal, e também da relação entre os diferentes níveis de gestão.

Do ponto de vista da articulação com a política de saúde, os dados gerados pelo Projeto SBBrasil forneceram subsídios importantes para a construção da Política Nacional de Saúde Bucal proposta em 2004, que ficou conhecida como "Brasil Sorridente" (Brasil16). Tal política surge num momento particularmente significativo, na medida em que, no plano nacional, a saúde bucal é colocada claramente como prioridade dentro do governo instalado a partir de 2003. Um considerável aumento no financiamento da área de saúde bucal, aliado a uma proposta de intervenção em que boa parte dos pontos é consensual, imprime ao "Brasil Sorridente" a característica de uma política de saúde bucal consistente, algo praticamente inédito neste campo.

Contudo, a proposta de incorporação de uma base epidemiológica, com vistas a um modelo de vigilância, e as perspectivas de continuidade de experiências como o SBBrasil ainda não estão claras no "Brasil Sorridente". É importante que o diagnóstico esteja articulado com as ações, mas isso não é suficiente para que a incorporação da epidemiologia à política de saúde bucal seja garantida. A definição de pontos importantes faz parte dessa agenda: a perio- 
dicidade e a amplitude de pesquisas avaliativas; o estabelecimento de indicadores e a sua respectiva vinculação a protocolos de intervenção; a definição clara do papel dos diferentes níveis de gestão na produção e disseminação de informações de saúde bucal; e a perspectiva de articulação com outros setores ligados à política de informação. Neste sentido, se o "Brasil Sorridente" pretende ser, de fato, uma política de Estado e não de governo, não deve se restringir a um pacote de medidas vinculadas às ações coletivas e assistenciais básicas e especializadas.

Em suma, considerando o conjunto de reflexões anteriores, as três principais iniciativas para a construção de diagnósticos de saúde bucal em nível nacional não se constituem apenas em um conjunto de dados gerados ao longo de 17 anos. A despeito de apresentarem características muito distintas (ver Quadro 1), expressam, como discutimos anteriormente, o amadurecimento técnico-científico, e também po- lítico, da epidemiologia e da saúde bucal coletiva, e tiveram sua importância em seu devido tempo. Foram fundamentais, portanto, para pavimentar o caminho de ambas.

\section{A produção científica em epidemiologia em saúde bucal na academia e nos serviços de saúde}

Um importante termômetro do desenvolvimento da epidemiologia, tanto do ponto de vista dos serviços quanto da academia, é a participação em conclaves da área. Desde 1990, quando de sua primeira edição na cidade de Campinas (SP), o Congresso Brasileiro de Epidemiologia, promovido pela Associação Brasileira de Pós-Graduação em Saúde Coletiva (Abrasco), vem se firmando como o grande espaço para a divulgação e o debate a respeito da epidemiologia no País.

\begin{tabular}{|c|c|c|c|}
\hline \multicolumn{4}{|c|}{$\begin{array}{l}\text { Quadro } 1 \\
\text { Principais características dos três levantamentos epidemiológicos realizados no Brasil. }\end{array}$} \\
\hline Categorias de análise & 1986 & 1996 & 2003 \\
\hline $\begin{array}{l}\text { Cenário político- } \\
\text { sanitário }\end{array}$ & $\begin{array}{l}\text { - Redemocratização } \\
\text { do País (Nova República) } \\
\text { - Crescimento e amadurecimento } \\
\text { do Movimento Sanitário } \\
\text { - VIII Conferência } \\
\text { Nacional de Saúde } \\
\text { - Divisão Nacional de Saúde } \\
\text { Bucal (DNSB) }\end{array}$ & $\begin{array}{l}\text { - Primeiro mandato de FHC } \\
\text { - Democracia representativa } \\
\text { aparentemente consolidada } \\
\text { - Avanço na implantação } \\
\text { de uma vertente econômica } \\
\text { neoliberal } \\
\text { - Saúde bucal como área técnica } \\
\text { no Ministério da Saúde }\end{array}$ & $\begin{array}{l}\text { - Início do projeto no segundo } \\
\text { mandato de FHC e conclusão } \\
\text { no início do governo Lula } \\
\text { - Pouca ou nenhuma mudança } \\
\text { na política macroeconômica } \\
\text { - Política de saúde bucal priorizada } \\
\text { no conjunto de políticas públicas } \\
\text { - Rearticulação da Coordenação } \\
\text { Nacional de Saúde Bucal } \\
\text { - III Conferência Nacional } \\
\text { de Saúde Bucal }\end{array}$ \\
\hline $\begin{array}{l}\text { Cenário } \\
\text { epidemiológico }\end{array}$ & $\begin{array}{l}\text { - Alta prevalência e severidade } \\
\text { de cárie dentária em escolares } \\
\text { - Alto índice de edentulismo } \\
\text { em adultos e idosos } \\
\text { - Desigualdades regionais } \\
\text { no perfil epidemiológico }\end{array}$ & $\begin{array}{l}\text { - Tendência de queda na cárie } \\
\text { de população escolar } \\
\text { - Persistência de desigualdades } \\
\text { regionais }\end{array}$ & $\begin{array}{l}\text { - Confirmação na tendência } \\
\text { de declínio na cárie dentária } \\
\text { da população escolar (12 anos) } \\
\text { - Persistência de grandes } \\
\text { desigualdades regionais. } \\
\text { Concentração do declínio e de } \\
\text { melhores condições de saúde } \\
\text { bucal em área urbana de capitais } \\
\text { do Sul e Sudeste e em alunos } \\
\text { de escola privada } \\
\text { - Quadro de edentulismo } \\
\text { ainda alarmante } \\
\text { - Surgimento de outras } \\
\text { necessidades, como } \\
\text { as oclusopatias }\end{array}$ \\
\hline
\end{tabular}




\begin{tabular}{|c|c|c|c|}
\hline \multicolumn{4}{|c|}{ Quadro 1 (continuação) } \\
\hline Categorias de análise & 1986 & 1996 & 2003 \\
\hline $\begin{array}{l}\text { Características } \\
\text { metodológicas }\end{array}$ & $\begin{array}{l}\text { - Delineamento amostral } \\
\text { probabilístico com } \\
\text { representatividade em nível } \\
\text { macrorregional } \\
\text { - Avaliação de cárie dentária, } \\
\text { doença periodontal } \\
\text { e edentulismo } \\
\text { - Zona urbana de } 16 \text { capitais } \\
\text { - Grupos etários de escolares } \\
\text { a idosos }\end{array}$ & $\begin{array}{l}\text { - Modelo amostral } \\
\text { não-probabilístico } \\
\text { - Avaliação somente de cárie } \\
\text { dentária em escolares } \\
\text { de } 6 \text { a } 12 \text { anos } \\
\text { - Zona urbana de } 27 \text { capitais } \\
\text { e Distrito Federal }\end{array}$ & $\begin{array}{l}\text { Delineamento amostral } \\
\text { probabilístico com } \\
\text { representatividade em nível } \\
\text { macrorregional } \\
\text { - Avaliação de cárie dentária, } \\
\text { doença periodontal, } \\
\text { edentulismo, oclusopatias } \\
\text { e fluorose. Verificação } \\
\text { de condições socioeconômicas } \\
\text { e acesso a serviços } \\
\text { - Zona urbana e rural de } 250 \\
\text { municípios de diferentes portes } \\
\text { populacionais (de menos } \\
\text { de } 5 \text { mil a mais de } 100 \text { mil } \\
\text { habitantes) } \\
\text { Seis grupos etários, de bebês } \\
\text { a idosos }\end{array}$ \\
\hline $\begin{array}{l}\text { Articulação com } \\
\text { a política de saúde }\end{array}$ & $\begin{array}{l}\text { - Vinculado ao Programa } \\
\text { de Prevenção de Cárie } \\
\text { Dentária - Precad } \\
\text { - Sem continuidade }\end{array}$ & $\begin{array}{l}\text { - Nenhuma política de saúde } \\
\text { bucal definida } \\
\text { - Sem continuidade }\end{array}$ & $\begin{array}{l}\text { - Articulado à Política } \\
\text { Nacional de Saúde Bucal } \\
\text { (“Brasil Sorridente”) } \\
\text { - Continuidade ainda indefinida }\end{array}$ \\
\hline $\begin{array}{l}\text { Capilarização para } \\
\text { estados e municípios } \\
\text { e incorporação } \\
\text { da metodologia }\end{array}$ & - Nenhuma & - Nenhuma & $\begin{array}{l}\text { - Restrita inicialmente à fase } \\
\text { de execução nos } 250 \\
\text { municípios sorteados } \\
\text { - Indícios claros de incorporação } \\
\text { metodológica em estados } \\
\text { do Nordeste, Sudeste e Sul, que } \\
\text { ampliaram a amostra estadual } \\
\text { - Absorção e incorporação } \\
\text { da metodologia pela academia }\end{array}$ \\
\hline
\end{tabular}

Desde 1990, seis edições do evento já aconteceram, com periodicidade variando entre dois e três anos. Embora reconhecendo que a participação em congressos é influenciada pelas diferentes possibilidades de deslocamento, mediada pela condição econômica dos programas e das regiões, de uma maneira geral, observar a participação de uma determinada área ao longo das edições do congresso pode indicar o modo como ela vem se desenvolvendo.

Em estudo feito por Souza17, a participação da saúde bucal nos congressos de epidemiologia foi avaliada até sua quarta edição em 1998. Com base nos anais dos congressos, a pesquisadora avaliou os resumos de todos os trabalhos enquadrados como pertencentes à área de saúde bucal, levando em conta determinadas características, tais como a região, a instituição, a classificação temática e a classificação metodológica. Ampliamos o estudo da pesquisadora, incluindo as análises dos anos de 2002 e 2004.

É nítido, como se pode observar no gráfico 1, o crescimento da participação da saúde bucal nos congressos. Em termos percentuais, de uma participação relativa de menos de um por cento em relação ao total de trabalhos em 1990 , atinge-se quase quatro por cento em 2004, cerca de cinco vezes mais. O incremento maior se dá até o ano de 1998, chegando a uma quase estabilização entre 1998 e 2004, embora em números absolutos o aumento seja significativo. Há que se levar em conta que o próprio congresso cresceu consideravelmente desde 1990, passando de 375 trabalhos em sua primeira edição, para 3.546 em 2004, de modo que podemos observar que a epidemiologia em 
Gráfico 1

Trabalhos apresentados nos congressos de epidemiologia entre 1990 e 2004, segundo região.

Resultados mostrados em números absolutos e em percentual em relação ao total de trabalhos. Brasil, 2005.

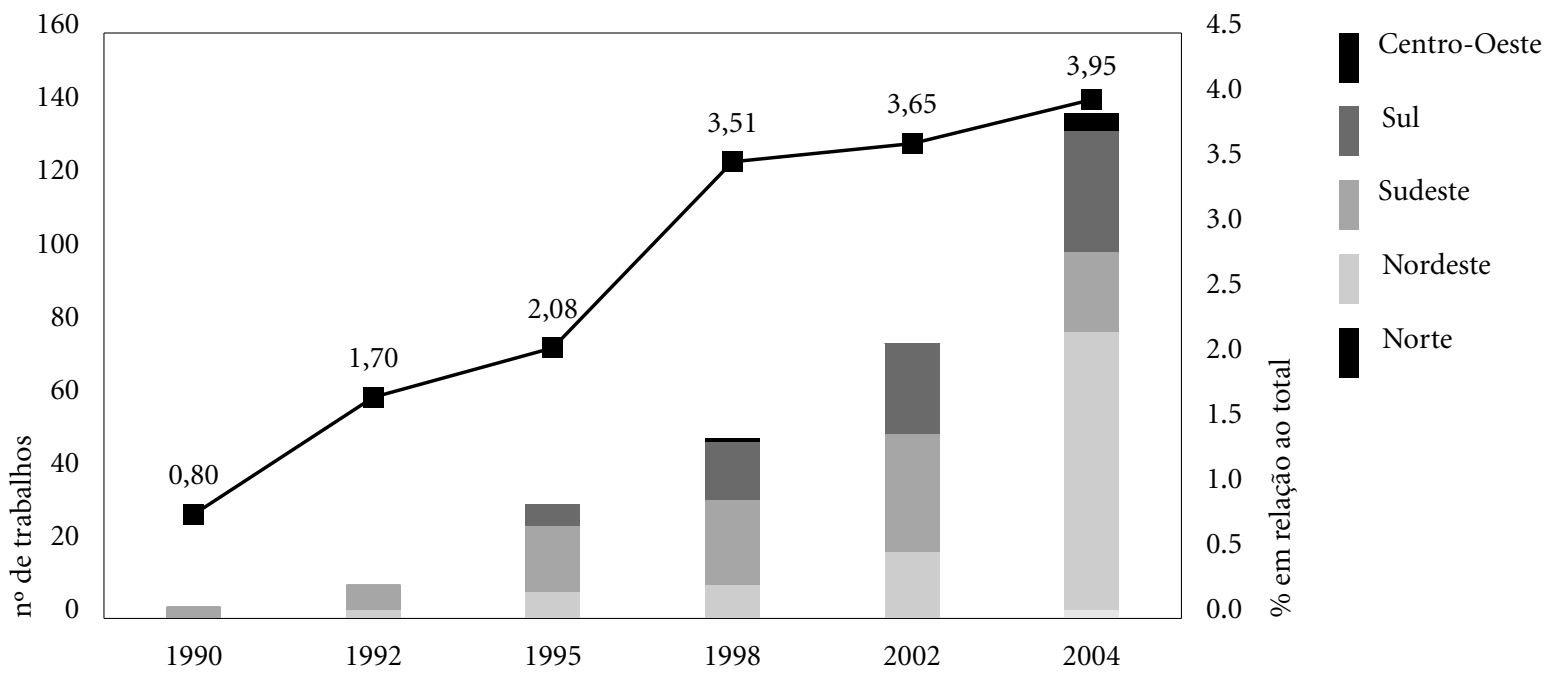

Fonte: Souza ${ }^{17}$ para os dados até 1998.

saúde bucal tem acompanhado o desenvolvimento da área como um todo.

Com relação à distribuição por regiões, há uma concentração maior nas regiões Nordeste, Sudeste e Sul, com pouca participação das regiões Norte e Centro-Oeste. Importante destacar, contudo, que a análise da participação por regiões é enviesada pelo local onde os congressos ocorrem. Nota-se que há uma presença maior das regiões Sul e Sudeste em 2002 (33\% e $43 \%$ dos trabalhos, respectivamente), quando o congresso foi realizado em Curitiba (PR); e uma maior participação do Nordeste (55\%), quando o evento foi realizado em Recife (PE), em 2004. De toda maneira, mesmo considerando este viés, esse comportamento, em seu conjunto, é esperado, pois se concentram, nestas regiões, o maior número de universidades (com cursos de odontologia), de institutos de pesquisa e de programas de pós-graduação. Em termos populacionais, $85 \%$ dos brasileiros se encontram nestas três regiões: $\mathrm{NE}=27,7 \%$, $\mathrm{SE}=42,6 \%$ e $\mathrm{S}=14,6 \%$ (Brasil 18 ).

Podemos admitir que boa parte da produção científica em epidemiologia em saúde bucal está concentrada em programas de pós-graduação em saúde coletiva ou em saúde bucal coletiva (e suas equivalentes nominações, tais como odontologia social, odontologia preventiva e social, odontologia em saúde coletiva, etc.). Considerando os dados de fevereiro de 2005 da Coordenação de Aperfeiçoamento de Pessoal de Nível Superior (Capes), a área de ciências da saúde responde por cerca de $20 \%$ do total de programas de pós-graduação, com 590 programas. A área de saúde coletiva possui 27 programas, sendo que, destes, 11 incluem cursos de doutorado, existindo, ainda, cinco cursos de mestrado profissionalizante. Deste total, 14 estão sediados na região Sudeste, seis estão na região Sul, sete no Nordeste e apenas um na região Centro-Oeste. A saúde bucal coletiva, por sua vez, está presente em 14 programas de pós-graduação na área de odontologia, seja como área de concentração ou como programa específico. Destes, três estão no Nordeste (PE e RN), dois na região Sul (RS e SC) e os nove restantes no Sudeste (oito em São Paulo e um em Minas Gerais) (Brasil19).

Tal raciocínio é coincidente com o estudo de Guimarães et al.20, o qual, a partir da análise do Diretório de Grupos de Pesquisa do CNPq (Conselho Nacional de Desenvolvimento Científico e Tecnológico), observou que $82,4 \%$ dos grupos de pesquisa no Brasil estão nas regiões Sudeste e Nordeste $(60,8 \%$ e $21,6 \%$, respectiva- 
mente). Ainda nesse mesmo estudo, os autores constataram que a "epidemiologia odontológica" responde por $1,2 \%$ das linhas de pesquisa associadas à especialidade epidemiologia, ocupando o 11 o lugar no Brasil entre os 12 principais temas.

Considerando esse padrão de distribuição, é compreensível constatar que as universidades respondem pela maior fatia da produção científica da epidemiologia em saúde bucal. Isoladamente, corresponde, em termos gerais, a $76 \%$ de toda a produção apresentada. Agregando a este percentual os casos em que existe uma parceria entre universidade e serviços, o total chega a $86 \%$.

A despeito de sua menor participação em termos proporcionais, os serviços de saúde têm demonstrado uma significativa participação nos congressos (quase um em cada quatro trabalhos tem a participação dos serviços, isoladamente ou em parceria). Este fato é relevante quando se considera que essa não é uma atividade comum nos serviços. A produção de dados epidemiológicos nos serviços de saúde bucal é, além de rara, pouco divulgada, ficando restrita ao ambiente do setor saúde, não raro sem articular-se com estratégias de planejamento e avaliação.

Uma outra observação interessante é com relação aos tipos de trabalho que são realizados e apresentados nos congressos. De um modo geral, os estudos de prevalência e os estudos de avaliação são predominantes. Um perfil inteiramente justificável, devido à tradição na epidemiologia em saúde bucal de produzir diagnósticos epidemiológicos como subsídio para as ações nos serviços de saúde. Estes diagnósticos ainda continuam sendo realizados pelas universidades, isoladamente ou em parceria (77\% e $12 \%$, respectivamente). Menos de $10 \%$ dos estudos de prevalência são conduzidos somente pelos serviços. Com relação aos estudos de avaliação, contudo, $22 \%$ são conduzidos unicamente pelos serviços e $6 \%$ em parceria com universidades, o que é positivo na medida em que demonstram uma preocupação com a avaliação de suas ações de saúde. Entretanto, o fato de $70 \%$ dos estudos avaliativos estarem concentrados exclusivamente na academia conduz a uma reflexão inevitável a respeito da real utilização dos mesmos. É provável que, em alguns deles, uma articulação universidade-serviço de fato ocorra, e os estudos avaliativos conduzidos pela academia façam parte de uma estratégia global de avaliação das ações de saú- de bucal. Contudo, o mais provável é que grande parte desses estudos permaneça como produção acadêmica, sem nenhum retorno significativo para os serviços.

Enfim, o que se pode observar a partir desta análise, é que o campo da epidemiologia em saúde bucal tem crescido de modo considerável, expressando-se na maior divulgação de sua produção científica. Este fato é relevante, na medida em que existe a possibilidade de que uma "inteligência epidemiológica" seja criada na academia e nos serviços, o que contribuirá, sobremaneira, para a consolidação de modelos assistenciais de base epidemiológica e, portanto, mais universais e eqüitativos, coadunantes com o ideário do SUS e da saúde bucal coletiva.

Evidentemente, diversas limitações, também aqui observadas nesta breve análise, têm que ser superadas. Entre elas, uma maior articulação entre a academia e os serviços de saúde, tendo aquela que romper com sua tradicional visão utilitarista dos serviços e estes aproveitarem a produção de conhecimentos de forma articulada, desenvolvendo mecanismos de incorporação de uma produção científica perene e de qualidade. Esta produção deverá apontar, fundamentalmente, para a possibilidade de uma maior compreensão da gênese das doenças bucais, bem como para a construção de diagnósticos que não apenas descrevam de modo asséptico a realidade da saúde bucal, mas, também, contribuam para a consolidação de estratégias de vigilância em saúde bucal na perspectiva de modelos de atenção universais e eqüitativos.

\section{Considerações finais}

Este artigo pretendeu introduzir uma reflexão a respeito do desenvolvimento da epidemiologia em saúde bucal e da saúde bucal coletiva, partindo da premissa que essas duas áreas apresentaram um processo compartilhado de amadurecimento no Brasil, o qual ainda está em vias de consolidação. Considerando os dois eixos de análise, dos quais destacamos apenas alguns aspectos relevantes, percebemos que este caminhar esteve e está condicionado pela conjuntura política que, em momentos distintos, proporcionou o crescimento da saúde bucal coletiva enquanto campo de atuação, de reflexão e de luta da saúde coletiva. A epidemiologia (e, por extensão, a "epidemiologia em saúde bucal"), ao mesmo tempo 
em que se consolida enquanto área de conhecimento no plano da produção científica e tecnológica no Brasil, articula-se com este movimento, proporcionando, de um lado, uma ferramenta que aproxima os modelos assistenciais em saúde bucal do ideário de universalidade, integralidade e eqüidade do SUS; e, de outro, aprofunda as discussões a respeito dos determinantes biopsicossociais das doenças bucais.

\section{Agradecimento}

Agradecemos ao professor Marco Aurélio de Anselmo Peres, da Universidade Federal de Santa Catarina (UFSC), pelas significativas contribuições à construção deste trabalho.

\section{Referências}

1. Last JM. A dictionary of epidemiology. New York: Oxford University Press; 1988.

2. Scliar M. Um olhar sobre a saúde pública. São Paulo: Scipione; 2003.

3. Goldbaum M. Epidemiologia em serviços de saúde. Cad Saúde Pública 1996; 12 (Supl 2):95-8.

4. Teixeira CF. Epidemiologia e planejamento de saúde. Rev C S Col 1999; 4(2):287-303.

5. Narvai PC. Odontologia e saúde bucal coletiva. São Paulo: Hucitec; 1994.

6. Zanetti CHG, Lima MAU, Ramos L, Costa MABT. Em busca de um paradigma de programação local em saúde bucal mais resolutivo no SUS. Divulg Saúde Debate 1996; (13):18-35.

7. Botazzo C. Saúde bucal coletiva: um conceito em permanente construção. Saúde Atual 1991; (1):14-23.

8. Brasil. Ministério da Saúde. Divisão Nacional de Saúde Bucal. Levantamento epidemiológico em saúde bucal: Brasil, zona urbana 1986. Brasília: MS; 1988. (Série C: Estudos e Projetos, 4).

9. Zanetti CHG. As marcas do mal-estar social no Sistema Nacional de Saúde: o caso das políticas de saúde bucal, no Brasil dos anos 80 [dissertação]. Rio de Janeiro: Escola Nacional de Saúde Pública, Fiocruz; 1993.

10. Roncalli AG. Levantamentos epidemiológicos em saúde bucal no Brasil. In: Peres MA, Antunes JLF, editores. Epidemiologia em saúde bucal. Rio de Janeiro: Guanabara Koogan; 2006.

11. Noronha JC, Soares LT. A política de saúde no Brasil nos anos 90. Rev C S Col 2001; 6(2):445-50.

12. Souza SMD. Levantamento epidemiológico em saúde bucal - cárie dental - 1a etapa. Jornal ABO Nacional 1996; nov-dez: 8B.
Esta reflexão é, evidentemente, limitada pelo espaço editorial, e alguns pontos fundamentais que aprofundam e corroboram esta tese não puderam ser analisados. De todo modo, outras análises se seguirão; e o próprio fato deste artigo fazer parte de um número da Ciência é Saúde Coletiva em que a saúde bucal coletiva é o principal objeto é, de certo modo, uma nítida constatação do que discutimos anteriormente.
13. Pinto VG. Projeto de levantamento epidemiológico nacional em saúde bucal não tem consistência. APCD Jornal 1996; nov-dez:15.

14. Roncalli AG, Frazão P, Pattussi MP, Araújo IC, Ely HC, Batista SM. Projeto SB2000: uma perspectiva para a consolidação da epidemiologia em saúde bucal coletiva. Rev Bra Odont em Saúde Col 2000; 1(2): 9-25.

15. Pereira AC, organizador. Odontologia em saúde coletiva: planejando ações e promovendo saúde. Porto Alegre: Artmed; 2003.

16. Brasil. Ministério da Saúde. Programa Brasil Sorridente. 2005 [acessado mar 2005]. Disponível em: http://portal.saude.gov.br/portal/saude/area.cfm?id_area=406.

17. Souza ECF. Pensando a participação da saúde bucal nos congressos de epidemiologia: que epidemiologia em saúde bucal? Rev C S Col 2000; 5 (Supl. 2000): 561.

18. Brasil. Ministério do Planejamento, Orçamento e Gestão. Instituto Brasileiro de Geografia e Estatística. Estimativa da população brasileira para 2005. 2005 (acessado 2005 abr). Disponível em: http:// www.datasus.gov.br.

19. Brasil. Ministério da Educação. Coordenação de Aperfeiçoamento de Pessoal de Nível Superior (Capes). Programas de mestrado e doutorado reconhecidos. 2005 (acessado 2005 abr). Disponível em: http:// www.capes.gov.br.

20. Guimarães R, Lourenço R, Cosac S. A pesquisa em epidemiologia no Brasil. Rev Saúde Pública 2001; 35(4):321-40.

Artigo apresentado em 21/06/2005

Aprovado em 30/08/2005

Versão final apresentada em 28/10/2005 